\title{
Influência da distribuição granulométrica na estabilidade dimensional de placas cerâmicas de base vermelha
}

\author{
(Influence of particle size distribution on the dimensional \\ stability of red ceramic tiles)

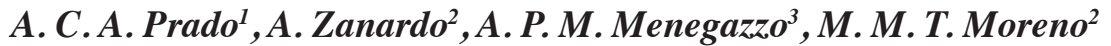 \\ ${ }^{l}$ Centro de Ciências Agrárias, Universidade Federal do Espírito Santo, R. Alto Universitário s/n, \\ Bairro Guararema, Alegre, ES \\ ${ }^{2}$ Departamento de Petrologia e Metalogenia, Instituto de Geociências e Ciências Exatas, Universidade Estadual \\ Paulista, Av. 24 A 1515, Bairro Bela Vista, Rio Claro, SP \\ ${ }^{3}$ Centro de Inovação Tecnológica/Centro Cerâmico do Brasil, R. Nossa Senhora do Carmo 96, \\ $J d$. Luciana, Santa Gertrudes, $S P$ \\ acaprado@gmail.com,azanardo@rc.unesp.br,mmoreno@rc.unesp.br,anapaula.ccb@terra.com.br
}

\begin{abstract}
Resumo
As propriedades do revestimento cerâmico queimado estão intrinsecamente ligadas às características da massa, dentre estas se encontram o tamanho, a distribuição, o formato e o arranjo das partículas. O efeito da distribuição granulométrica de partículas sobre a estabilidade dimensional de placas cerâmicas para revestimentos de base vermelha foi estudado em três massas, todas continham no mínimo 57\% de material advindo da Formação Corumbataí. Foram estudadas duas distribuições granulométricas - uma parecida com aquelas usadas no Pólo Cerâmico de Santa Gertrudes e, outra, com uma massa de grés. De uma maneira geral, granulações mais grossas, semelhantes à massa de Santa Gertrudes, variaram menos dimensionalmente quando as placas apresentaram médias e altas porosidades (absorção de água entre 3,0 e 10,0\%). Já, granulações mais finas, similares a massas de grés, foram necessárias para a produção de placas de baixa absorção (menor que 3,0\%).
\end{abstract}

Palavras-chave: distribuição granulométrica, estabilidade dimensional, revestimento cerâmico, formação Corumbataí, Pólo de Santa Gertrudes.

\begin{abstract}
The properties of final ceramic tiles are related with the mass characteristics, among them the size, shape, distribution and arrange of particles. The effect of particle size distribution on dimensional stability of red ceramic tiles was studied in three masses; all of them composed with, at minimum, 57\% of Corumbatai Formation's materials. Two particle size distributions were investigated: the first was similar to the masses that are used in the Santa Gertrudes Ceramic Pole's factories and the other was similar to the stoneware mass. In general, masses with larger particle sizes, similar to that of Santa Gertrudes, had greater dimensional stability in the products with 3 to $10 \%$ of water absorption. On the other hand, in the manufacture of low porosity tiles (water absorption capacity $<3 \%$ ) it is recommended the use of smaller grain size.
\end{abstract}

Keywords: particle size distribution, dimensional stability, ceramic tile, Corumbataí Formation, Santa Gertrudes Pole.

\section{INTRODUÇÃO}

Háquatro fatores principais que influemnas características de uma placa cerâmica para revestimento: 1) composição da massa; 2) distribuição granulométrica e formato das partículas; 3) grau de compactação antes da queima, denominado compacidade; e 4) condições de queima. Entre as características influenciadas por estes fatores encontra-se a estabilidade dimensional [1].

A distribuição granulométrica da massa cerâmica interfere na estabilidade dimensional à medida que o tamanho, o formato, a rugosidade e a homogeneização do pó determinam o preenchimento do molde de prensagem e, posteriormente, determinam os pontos de contato entre as partículas, pontos, estes, onde ocorrem as reações de sinterização.

Placas cerâmicas de base vermelha são fabricadas a partir de matérias-primas que contêm ferro. $\mathrm{O}$ maior pólo cerâmico brasileiro fabrica revestimentos de base vermelha e se situa ao redor da cidade de Santa Gertrudes, no estado de S. Paulo. Além do óxido de ferro, que varia de 3 a $6 \%$ e que está presente principalmente como hematita, a matéria-prima usada no pólo de Santa Gertrudes normalmente contém illita, feldspatos alcalinos, quartzo, montmorillonita, clorita, interestratificados de argilominerais e, em níveis localizados, carbonatos. É 
uma matéria-prima única advinda de uma das unidades sedimentares que formam a grande Bacia do Paraná: a Formação Corumbataí [2, 3].

A maioria das indústrias deste pólo prepara sua massa por meio de moagem a seco tradicional, que consiste em moagem primária em moinho de martelo, moagem secundária em moinho pendular, peneiramento, umidificação e estocagem em silos.

Tabela I - Distribuição granulométrica típica após a moagem a seco tradicional de material da Formação Corumbataí usada por uma indústria do Pólo Cerâmico de Santa Gertrudes.

[Table I - Particle size distribution of mass used in the Santa Gertrudes Ceramic Pole's factories after traditional dry grinding.]

\begin{tabular}{cc}
\hline $\begin{array}{c}\text { Diâmetro equivalente de } \\
\text { partícula } \Phi(\mu \mathrm{m})\end{array}$ & $\begin{array}{c}\text { Porcentagem Retida } \\
(\%)\end{array}$ \\
\hline$\Phi>350$ & 0 \\
$350>\Phi>250$ & 6,5 \\
$250>\Phi>180$ & 10,7 \\
$180>\Phi>150$ & 3,5 \\
$150>\Phi>106$ & 12,6 \\
$\Phi<106$ & 66,7 \\
\hline
\end{tabular}

Tabela II - Distribuição granulométrica após a moagem a seco de uma típica massa de grés [6].

Table II - Particle size distribution of stoneware mass after dry grinding [6].

\begin{tabular}{cc}
\hline Diâmetro de partícula & Porcentagem Retida $(\%)$ \\
$\Phi(\mu \mathrm{m})$ & 0,10 \\
$\Phi>200$ & 1,10 \\
$200>\Phi>125$ & 7,20 \\
$125>\Phi>63$ & 3,10 \\
$63>\Phi>40$ & 88,50 \\
$\Phi<40$ & \\
\hline
\end{tabular}

O efeito da distribuição do tamanho de partícula sobre as propriedades das placas cerâmicas, antes e após a queima, compostas majoritariamente pelo material da Formação Corumbataí, ainda não foi devidamente estudado. Este estudo propõe verificar este efeito particularmente sobre a estabilidade dimensional dos revestimentos. Para tanto, este trabalho estudou o comportamento de massas usando como referências duas distribuições granulométricas ambas obtidas por meio da moagem a seco. A primeira é a distribuição típica de uma fábrica de Santa Gertrudes (descrita na Tabela I) e a segunda, distribuição semelhante a uma massa de grés (Tabela II).

A escolha pelo método de cominuição por moagem a seco adotado nesta pesquisa se deu por dois motivos: ainda é necessário estudos científicos, técnicos e financeiros mais aprofundados para a implementação de moagem a úmido para cominuir o material da Formação Corumbataí; e apesar da sabida superioridade das características do pó atomizado (obtido por moagem a úmido e atomização) sobre o pó obtido por meio da moagem a seco [4], há processos que são capazes de fornecer um pó com características similares ao do pó atomizado, como, por exemplo, a moagem a seco em moinho vertical a rolos acoplada com o sistema de umidificação por re-granulação [5].

\section{PROCEDIMENTO EXPERIMENTAL}

Três massas foram estudadas, uma composta pelo material advindo de um nível rico em albita da Formação Corumbataí, outra por $70 \%$ deste material albítico e $30 \%$ de caulim, e a última por $57 \%$ do nível da formação, $23 \%$ de caulim e $20 \%$ de diabásio. As composições química e mineralógica, bem como as densidades reais, das matériasprimas foram determinadas e descritas [7].

O material da Formação (Fm.) Corumbataí foi coletado na jazida Cruzeiro, sediada no município de Limeira, SP. A fonte do caulim usado na composição das misturas foi a mineração Romer de S. Paulo, SP. O diabásio adveio da mineração Cavinato localizada no município de Limeira, SP. A argila da Formação Corumbataí foi primeiramente seca

Tabela III - Porcentagens em massa de cada matéria-prima/modo final de cominuição usada na preparação das misturas. [Table III - Composition (wt\%) of the ceramic mass.]

\begin{tabular}{|c|c|c|c|c|c|c|}
\hline Matéria-prima & M1 & $\begin{array}{c}\text { M1 } \\
\text { grossa }\end{array}$ & M2 & $\begin{array}{c}\text { M2 } \\
\text { grossa }\end{array}$ & M3 & M3 grossa \\
\hline $\begin{array}{l}\text { Siltito/argilito da Fm. Corumbataí moído em } \\
\text { moinho de bolas por } 1 \mathrm{~h}\end{array}$ & & $100 \%$ & & $57 \%$ & & $70 \%$ \\
\hline $\begin{array}{l}\text { Siltito/argilito da Fm. Corumbataí moído em } \\
\text { moinho de bolas por } 8 \mathrm{~h}\end{array}$ & $100 \%$ & & $57 \%$ & & $70 \%$ & \\
\hline Diabásio moído em moinho cruzeta & & & & $20 \%$ & & \\
\hline Diabásio moído em moinho de bolas por $8,5 \mathrm{~h}$ & & & $20 \%$ & & & \\
\hline Caulim & & & $23 \%$ & $23 \%$ & $30 \%$ & $30 \%$ \\
\hline
\end{tabular}


ao ar, britada e moída em moinho cruzeta. Posteriormente, para a obtenção das duas granulometrias desejadas, a argila foi moída em moinho de bolas a seco por dois $1 \mathrm{~h}$ e $8 \mathrm{~h}$. O diabásio foi coletado na jazida já previamente britado. Em laboratório, foi moído em moinho cruzeta e uma parte dele foi moída em moinho de bolas a seco por $8,5 \mathrm{~h}$. O caulim já estava beneficiado, todas suas partículas apresentavam tamanhos inferiores a $45 \mu \mathrm{m}$. As proporções de cada matériaprima e o respectivo modo de preparo da composição são relatadas na Tabela III.

A distribuição granulométrica foi determinada por peneiramento a úmido com peneiras com abertura de 180 , 150,62 e $45 \mu \mathrm{m}$.

Após a verificação da distribuição granulométrica, as amostras foram umidificadas com aproximadamente $10 \%$ de água, granuladas, secas até aproximadamente $6,5 \%$ de umidade, re-granuladas e deixadas em descanso por $48 \mathrm{~h}$ para homogeneizar.

Corpos-de-prova foram prensados e, em seqüência, secos em estufa a $110{ }^{\circ} \mathrm{C}$ por $24 \mathrm{~h}$. A pressão de prensagem e a densidade a verde foram controladas com o objetivo dos corpos alcançarem uma compacidade (quociente entre a densidade da peça seca sobre a densidade real da massa) média de 0,69. Existe para cada massa e revestimento cerâmico pretendido um valor ideal ou faixa de valores ideais de compacidade. Já foram feitos testes para determinar este valor ou faixa de valores para massas compostas primordialmente pela Formação Corumbataí, os resultados indicaram que a compacidade de 0,69 resulta em boa estabilidade dimensional das peças cerâmicas após a queima [7].

Cinco corpos de cada amostra foram queimados em forno gradiente em temperaturas que variaram de 990 a 1150 ${ }^{\circ} \mathrm{C}$. Características físicas dos corpos foram determinadas e a média dos resultados dos cinco corpos-de-prova foi calculada.

Acaracterização consistiu em determinar absorção deágua (AA), a retração linear total (RLT), a porosidade aparente ou aberta (PA) e a porosidade total (Pt). Os procedimentos para determinação da AA seguiram as recomendações da norma ABNT [8]. A RLT foi determinada pela diferença relativa entre o comprimento da peça queimada e o comprimento da peça após a prensagem. E, as porosidades (aparente e total), segundo as seguintes equações:

$$
\begin{aligned}
& \operatorname{PA}(\%)=\frac{M_{u}-M_{s}}{M_{u}-M_{i}} \times 100 \\
& \operatorname{Pt}(\%)=1-\frac{M_{s}}{\left(M_{u}-M_{i}\right) \times D R} \times 100
\end{aligned}
$$

onde $\mathrm{M}_{\mathrm{s}}$ é a massa da peça seca usada para a determinação da absorção de água, $\mathrm{M}_{u}$ a massa desta mesma peça úmida, $\mathrm{M}_{\mathrm{i}}$ a massa desta totalmente imersa em água e DR é a densidade real da amostra determinada por picnometria de hélio. Os resultados das amostras com a mesma composição e granulometrias diferentes foram avaliados considerando a média de cada uma das características. A tendência à estabilidade dimensional foi determinada por meio da análise de diagramas de gresificação. As curvas da retração linear versus temperatura de queima foram mostradas novamente em detalhe dentro dos diagramas de gresificação, onde se destacaram os pontos 1, 2, 3 e 4 que correspondem respectivamente às absorções de água de $10,0 \%, 6,0 \%$, $3,0 \%$ e $0,5 \%$ e o ponto 5 correspondente a uma retração linear $0,25 \%$ menor do que a do ponto 4 . Dessa forma, a inclinação das curvas entre os pontos 1 e 2 avalia a variação dimensional do revestimento enquanto a absorção passa de 10,0 para $6,0 \%$ compatíveis com o grupo BIIb especificado [8]; entre os pontos 2 e 3 a variação dimensional das peças com absorção entre 6,0 e 3,0\% (grupo BIIa); pontos 3 a 4, a variação dimensional quando as peças apresentam absorção compatíveis do grés; e entre os pontos 4 e 5 , a variação dimensional com a temperatura de queima de peças tipo porcelanato esmaltado.

\section{RESULTADOS}

Os resultados dos ensaios granulométricos estão listados na Tabela IV. Estes resultados demonstram que as porcentagens em peso de partículas da mesma faixa de

Tabela IV - Distribuição granulométrica das amostras (\% em massa).

[Table IV - Particle size distribution of samples (wt.\%).]

\begin{tabular}{ccccccc}
\hline $\begin{array}{c}\text { Tamanho equivalente } \\
\text { da partícula }-\Phi(\mu \mathrm{m})\end{array}$ & M1 & $\begin{array}{c}\text { M1 } \\
\text { grossa }\end{array}$ & M2 & $\begin{array}{c}\text { M2 } \\
\text { grossa }\end{array}$ & M3 & $\begin{array}{c}\text { M3 } \\
\text { grossa }\end{array}$ \\
\hline$\Phi>180$ & $<0,1$ & 11,7 & $<0,1$ & 3,7 & $<0,1$ & 7,5 \\
$180>\Phi>150$ & 0,1 & 5,5 & $<0,1$ & 3,2 & 0,2 & 4,4 \\
$150>\Phi>62$ & 2,7 & 15,8 & 2,5 & 15,9 & 5,7 & 12,5 \\
$62>\Phi>45$ & 4,3 & 5,8 & 2,8 & 4,9 & 4,1 & 3,5 \\
$\Phi<45$ & 92,6 & 61,2 & 94,6 & 72,3 & 90,0 & 72,1 \\
\hline
\end{tabular}


tamanhos de M1, M2 e M3 são semelhantes aos da massa de grés [6]. Por sua vez, os tamanhos das partículas de M1 grossa, M2 grossa e M3 grossa são mais parecidos com os de uma massa usada em uma indústria do Pólo Cerâmico de Santa Gertrudes que produz pisos do tipo BIIb.

As Figs. 1 e 2 mostram, respectivamente, os diagramas de gresificação e a influência da temperatura de queima sobre as porosidades aberta e total da massa M1 em duas distribuições granulométricas. As variações da retração linear com a temperatura das amostras M1 e M1 grossa na faixa de absorção de água entre 10,0 e 6,0\% (entre os pontos 1 e 2) são similares. Já, entre 6,0 e 3,0\%, a mudança da retração de M1 foi menor do que o de M1 grossa, devido ao melhor empacotamento das partículas da massa M1 em relação à $\mathrm{M} 1$ grossa, o que proporcionou maior número de contatos entre as partículas. Por outro lado, verifica-se que o maior tamanho das partículas dificultou a sinterização, além da maior refratariedade. Observa-se que a amostra M1 grossa retraiu menos. A curva da retração com a temperatura apresentou inversão da inclinação durante a redução da porosidade na faixa de AA de 3,0 a $0,5 \%$ (intervalo entre os pontos 3 e 4). Portanto, a porosidade aberta ou aparente ainda não estava minimizada, muito menos anulada, quando a peça começou a expandir (ver Fig. 2). A porosidade aberta continuou a diminuir com a temperatura até valores de AA inferiores a $0,5 \%$, porém neste ponto, o aumento da porosidade total com a temperatura já era brusco, ou seja, a porosidade fechada (que é a diferença entre a porosidade total e a aberta) cresceu de modo abrupto.

Um trabalho demonstrou que o principal fundente de massas compostas pelo material da Formação Corumbataí é a illita [7]. A illita durante a sinterização gera grande quantidade de fase líquida de baixa viscosidade, que acoplada à geração de gases oriundos de transformações químicas que ocorrem principalmente com a hematita (também presente na Formação Corumbataí), torna a peça cerâmica mais suscetível a inchaços (super-queima) e a deformações (deformação piroplástica) $[9,10]$. Portanto, o aumento da temperatura de queima de M1 grossa, necessário para atingir o mesmo nível de absorção de água, reduziu a viscosidade da fase líquida e gerou maior quantidade de gases. Dessa forma, a pressão que a fase líquida exercia para o fechamento dos poros foi superada pela pressão que os gases exerciam para o aumento do volume dos poros já na faixa de AA de 3,0 a 0,5\% na amostra M1 grossa.

O mesmo efeito da distribuição granulométrica sobre as propriedades das placas cerâmicas foi verificado na amostra M2, porém a uma proporção um pouco menor. Isto pode ser atribuído ao fato de M2 grossa não conter tantas partículas grossas quanto M1 grossa (Tabela IV). O aumento das temperaturas de sinterização de $\mathrm{M} 2$ grossa em relação a M2 não foi tão alto, sendo de aproximadamente 10 a $15^{\circ} \mathrm{C}$ (ver o diagrama de gresificação mostrado na Fig. 3). Nas faixas de absorção de $0,5 \%<\mathrm{AA} \leq 3,0 \%$ (destacados pelos pontos 4 e 3 ), de $3,0 \%<\mathrm{AA} \leq 6,0 \%$ (pontos 3 e 2) e de $6,0 \%<$ $\mathrm{AA} \leq 10,0 \%$ (pontos 2 e 1 ), as sensibilidades da retração linear com a temperatura de M2 grossa foi menor do que

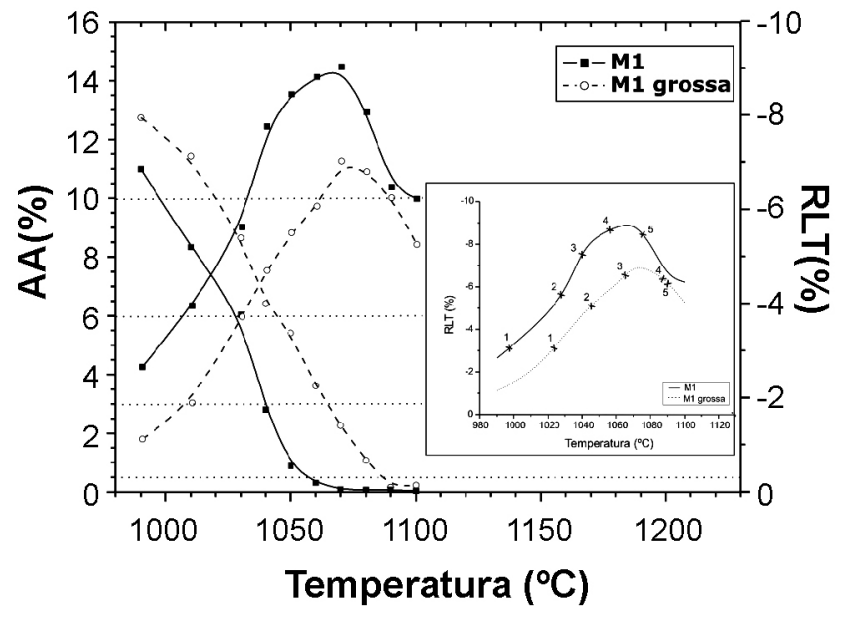

Figura 1: Diagrama de gresificação da massa M1 em duas distribuições granulométricas.

[Figure 1: Gresification diagram of M1 mass in two particle size distributions.]
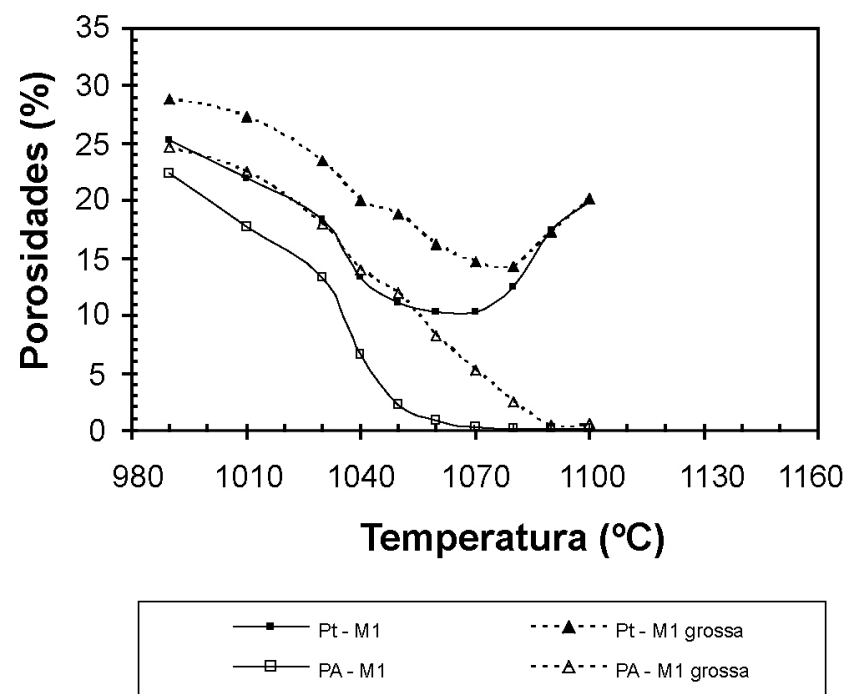

Figura 2: Variação das porosidades aberta e total com a temperatura de M1 em duas distribuições granulométricas.

[Figure 2: Open and total porosities vs. firing temperature of M1 in two particle size distribution.]

M2 . Portanto, para a produção de revestimentos cerâmicos de média a alta porosidade, a partir de uma massa composta por uma argila fundente (material da Fm. Corumbataí), argila refratária (caulim) mais o diabásio (que é um material que funde em temperaturas relativamente altas, mas produz fase líquida de baixa viscosidade) [11], do ponto de vista dimensional, é aconselhável trabalhar com granulometrias de partículas mais grossas. Por outro lado, antes de minimizar a porosidade aberta, a peça começou a expandir. Isto foi detectado pela ausência de patamar na curva da retração linear versus temperatura e pelas inclinações das curvas de variação das porosidades (a inclinação da curva da porosidade total mudou antes que a porosidade aparente tornar-se praticamente nula - ver Fig. 4). Assim, a superação da pressão dos gases inclusos nos poros sob a tensão 


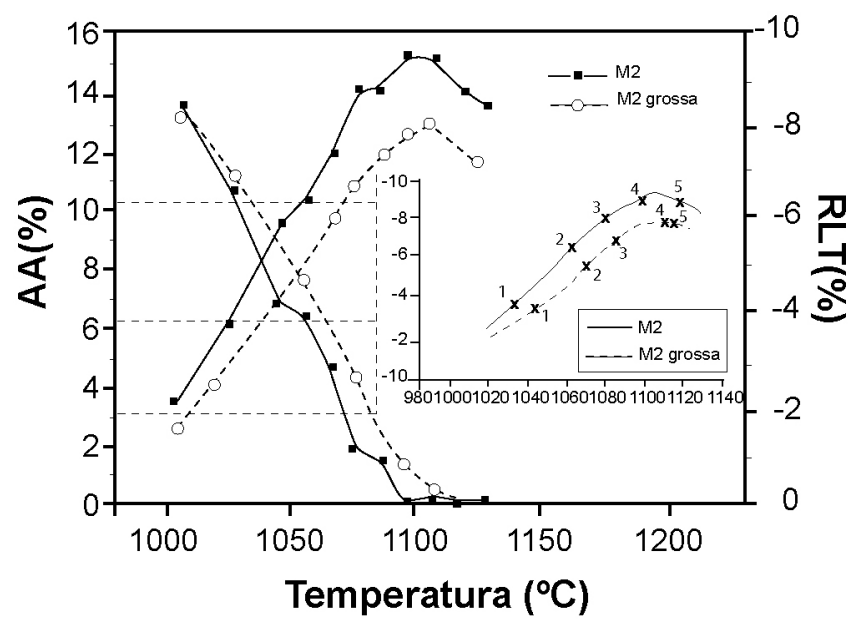

Figura 3: Diagrama de gresificação da amostra M2 em duas distribuições granulométricas.

[Figure 3: Gresification diagram of M2 sample in two particle size distributions.]
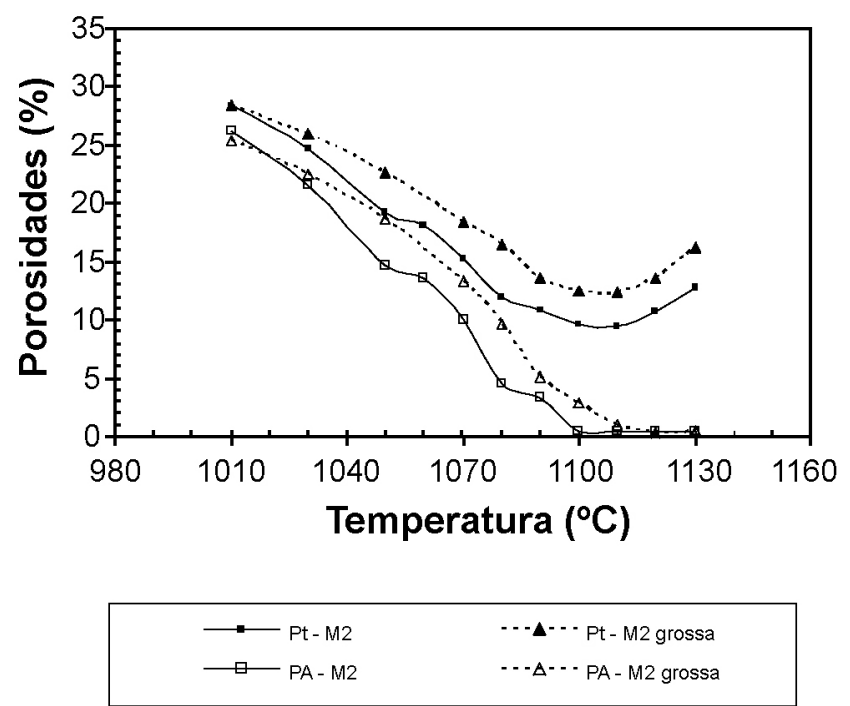

Figura 4: Variação das porosidades total e aberta com a temperatura da amostra M2 em duas distribuições granulométricas.

[Figure 4: Open and total porosities vs. firing temperature of M2 in two particle size distributions.]

superficial da fase líquida ocorreu antes do fechamento dos poros abertos. Como uma consequiência não é possível a produção de porcelanato com a amostra M2 grossa.

$\mathrm{O}$ efeito do aumento do tamanho das partículas em M3 foi mais significante. A Fig. 5 mostra os diagramas de gresificação de M3 com as duas granulações. M3 grossa é muito refratária, a absorção de água ainda estava em torno de $6 \%$ quando ocorreu a inversão da curva da retração. A porosidade aberta não se anulou, muito pelo contrário, até nas mais altas temperaturas, a porosidade aberta era em torno 9\% (ver Fig. 6). É possível que o efeito da distribuição de partículas numa faixa de maior tamanho tenha sido mais grave na amostra M3 grossa por causa das distribuições granulométricas muito distintas das duas matériasprimas usadas para compor essa amostra (material da Fm. Corumbataí moído grosso + caulim). O caulim é composto por partículas finas, praticamente todas menores que $45 \mu \mathrm{m}$. O material da Formação Corumbataí contém mais de 17\% de agregados maiores que $150 \mu \mathrm{m}$. A parte mais fina dessa mistura, o caulim, é refratária e, a outra parte, fundente. Os fragmentos maiores ficaram envoltos pela matriz muito rica em caulim, desse modo, a fusão ocorreu em núcleos isolados pelo material refratário, dificultando a sinterização pela falta de homogeneidade, com a retração permanecendo constante por aproximadamente $30^{\circ} \mathrm{C}$ (Fig. 5).

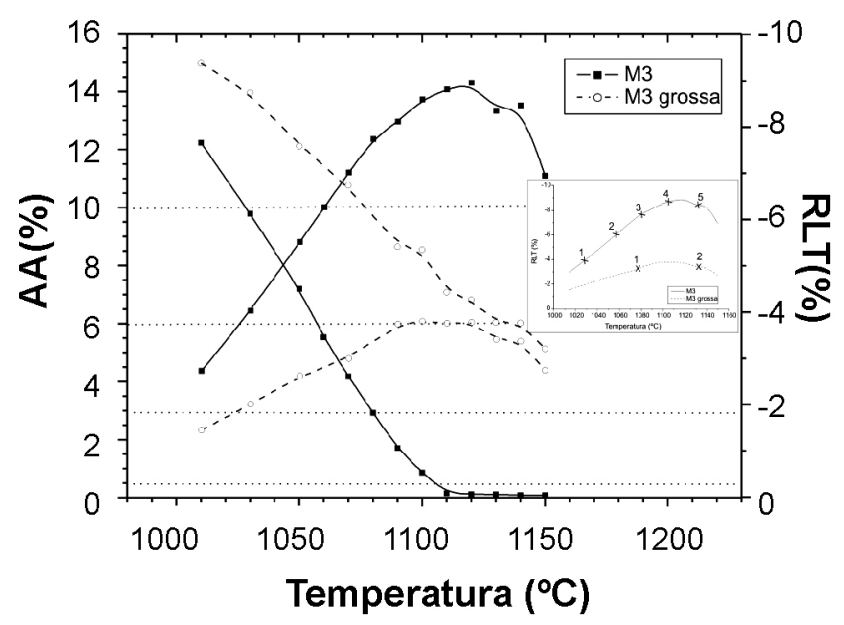

Figura 5: Diagrama de gresificação de M3 em duas distribuições granulométricas.

[Figure 5: Gresification diagram of M3 in two particle size distributions.]
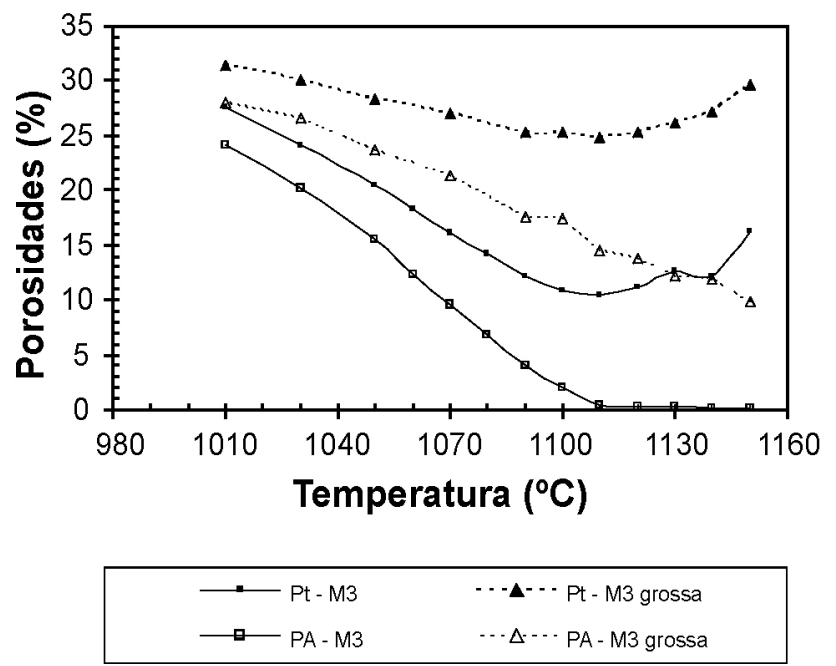

Figura 6: Variação das porosidades total e aberta com a temperatura M3 em duas distribuições granulométricas.

[Figure 6: Open and total porosities vs. firing temperature of M3 in two particle size distributions.] 


\section{CONCLUSÕES}

Distribuições granulométricas semelhantes às empregadas atualmente no Pólo Cerâmico de Santa Gertrudes não foram propícias para a fabricação de placas cerâmicas de baixa porosidade. A granulação mais grossa reduziu os pontos de contato entre as partículas e, consequientemente, a formação de fase líquida e as reações foram tardias em relação às massas com partículas de menores tamanhos. Ou seja, a temperatura de queima necessária para o fechamento dos poros foi maior. Isto tornou as amostras com granulação mais grossa instáveis dimensionalmente quando a porosidade/absorção de água pretendida para o produto era baixa. Por outro lado, quando o objetivo era obter produtos com média a alta absorção de água $(3,0<$ AA $\leq 10,0 \%$ ), a maior estabilidade dimensional geralmente foi alcançada com massas com granulometrias mais grossas.

\section{AGRADECIMENTOS}

À FAPESP (Proc. 03/01123-7) e ao CNPq (Procs. 141051/2005-1, 305815/2005-9 e 470573/2006-6).

\section{REFERÊNCIAS}

[1] A. Barba, V. Beltrán, C. Felíu, J. Garcia, F. Ginés, E. Sánchez, V. Sanz, Materias primas para la fabricación de suportes de baldosas cerámicas, $2^{\text {a }}$ Ed., Instituto de Tecnología Cerámica - ITC/AICE - Castañeda, Castellón, Espanha (2002) 292p.

[2] M. R. Masson, S. R. Christofoletti, H. R. Thomazella,
A. Fugie, A. Zanardo, V. Alegre, Cerâmica Industrial 5, 6 (2000) 24.

[3] M. Cabral Júnior, J. F. M. Motta, I. S. de C. Mello, L.C. Tanno, A. Sintoni, E.D. Salvador, L. A. Chieregatti, Geociências 20, 1-2 (2001) 105.

[4] J. L. Amorós, A. Moreno, M. J. Orts, A. Escardino, Bol. Soc. Esp. Cerámica y Vidrio 29, 3 (1990) 151.

[5] Associazione Costruttori Italiani Macchine Attrezzature per Ceramica - ACIMAC, Preparazione materie prime e formutura di piastrelle ceramich, Modena/S.A.L.A., Modena, Itália [1988-2001], 89-112/263-276.

[6] J. L. Amorós, V. Bagan, M. J. Orts, A. Escardino, Bol. Soc. Esp. Cerámica y Vidrio 27, 5 (1988) 273.

[7] A. C. A. Prado, Placas cerâmicas para revestimento de baixa absorção de água e estabilidade dimensional confeccionadas por moagem a seco usando o material da Formação Corumbataí, Tese (Doutorado em Geociências), Instituto de Geociências e Ciências Exatas, Universidade Estadual Paulista, Rio Claro, SP (2003) 203f.

[8] ABNT, "Placas cerâmicas para revestimentos: especificação e métodos de ensaios", NBR 13818. Rio de Janeiro, RJ (1997) 78p.

[9] B. A. Escardino, A. J. L. Amorós, N. J. E. Enrique, Cerámica Inf. 84 (1981) 211.

[10] V. A. Balaguer Sales, V. M. Huesa Ballester, F. M. Miralles Torla, E. Algora Pérez, Técnica Cerámica 187 (1990) 578.

[11] W. Teixeira, M. C. M. de Toledo, T. R. Fairchild, F. Taioli, Decifrando a Terra, Oficina de Textos, S. Paulo, SP (2000) 333p.

(Rec. 28/02/08, Rev. 08/04/2008, Ac. 26/05/2008) 